\title{
Seasonal changes in picocyanobacterial diversity as revealed by pyrosequencing in temperate waters of the East China Sea and the East Sea
}

\author{
Dong Han Choi ${ }^{1}$, Jae Hoon $\mathrm{Noh}^{2, *}$, JaeSeol Shim ${ }^{3}$ \\ ${ }^{1}$ Marine Biotechnology Research Division, ${ }^{2}$ Marine Ecosystem Research Division and ${ }^{3}$ Operational Ocean Science and \\ Technology Department, Korea Institute of Ocean Science and Technology, Ansan 426-744, Republic of Korea
}

\begin{abstract}
To elucidate the seasonal and spatial changes in picocyanobacterial diversity in temperate waters, the abundance and genetic diversity of picocyanobacteria and environmental variables were investigated at 3 stations located in the East China Sea and the East Sea. Barcoded amplicon pyrosequencing of 16S-23S internal transcribed spacer sequences was applied to study picocyanobacterial diversity using 36 samples. Through pyrosequencing, sequences belonging to 27 distinct Synechococcus and Prochlorococcus clades were retrieved, which showed high picocyanobacterial diversity and obvious seasonal variation in marginal waters. The coastal and cold water-adapted Synechococcus Clades I and IV were dominant during winter and spring, whereas the warm water-adapted Synechococcus Clade II and Prochlorococcus HLII ecotype were dominant during the summer and autumn. Further, Synechococcus Clades III, V, VII and 5.3-I as well as Prochlorococcus LLI opportunistically occupied distinct niches in the summer and early winter. In these temperate marginal seas, the seasonal distribution of picocyanobacterial diversity was mainly controlled by temperature and nutrient level. In addition, the seasonal circulation pattern of adjacent water masses was a key determinant of the physicochemical properties of water and consequently of picocyanobacterial diversity.
\end{abstract}

KEY WORDS: Synechococcus - Prochlorococcus - Diversity - East China Sea - East Sea · Pyroseqencing

\section{INTRODUCTION}

In marine environments, Synechococcus and Prochlorococcus are the dominant cyanobacteria, and they are known to be important primary producers (Li 1994, Liu et al. 1997, Jardillier et al. 2010). Prochlorococcus is more abundant in oligotrophic and tropical open oceans, whereas Synechococcus dominates in mesotrophic coastal waters and in upwelling regions (Partensky et al. 1999).

Picocyanobacterial diversity has been studied using various genetic markers, such as 16S rRNA (Fuller et al. 2003), the 16S-23S internal transcribed spacer (ITS; Rocap et al. 2002, Ahlgren \& Rocap 2006, Choi \&
Noh 2009, Mella-Flores et al. 2011, Huang et al. 2012), nitrogen regulatory gene (ntc $A_{;}$Penno et al. 2006, Post et al. 2011), nitrate reductase (narB; Jenkins et al. 2006, Paerl et al. 2008), RNA polymerase (rpoC1; Toledo \& Palenik 1997, Mühling et al. 2005) and cytochrome b6 subunit (petB; Mazard et al. 2012). These studies have revealed the existence of diverse Synechococcus and Prochlorococcus clades or ecotypes. Most studies of picocyanobacterial distribution in marine environments have been conducted using dotblot hybridization and real-time quantitative polymerase chain reaction (qPCR) methods using cladespecific probes (Fuller et al. 2003, Zwirglmaier et al. 2008, Tai \& Palenik 2009, Post et al. 2011, Ahlgren \& 
Rocap 2012) or terminal restriction fragment length polymorphism (Lavin et al. 2008). Recently, barcoded pyrosequencing methods that identify short taxonomic molecular markers via 454 sequencing technologies have been used to analyze microbial diversity in various environments (Binladen et al. 2007, Qian et al. 2011). This method allows many samples to be analyzed simultaneously and produces a large number of sequence reads for community analyses. Thus, using this method, one can elucidate microbial diversity based on sequences, as in a clone library. Three recent studies examined picocyanobacterial diversity via the pyrosequencing of 16S rDNA (Post et al. 2011) and 16S-23S ITS sequences (Choi et al. 2011, Choi 2012), but the pyrosequencing of 16S rDNA sequences could not discriminate all Synechococcus clades due to high sequence similarities among clades. However, a latitudinal distribution of picocyanobacterial diversity was successfully revealed via the pyrosequencing of 16S-23S ITS sequences (Choi et al. 2011).

Although many studies have examined the distribution of Synechococcus in various oceanic regions, few studies have investigated seasonal variation in picocyanobacterial diversity in marine environments (Fuller et al. 2005, Tai \& Palenik 2009, Post et al. 2011). In seasonal studies conducted in the subtropical Gulf of Aqaba and in a coastal monitoring site off the California coast, Synechococcus Clade II and Clades I and IV, respectively, were dominant throughout the year. The East China Sea (ECS) and the East Sea/Sea of Japan (ES) show seasonal changes in water temperature typical of a temperate region and, therefore, exhibit dynamic changes in the physicochemical environment. In the present study, we used pyrosequencing of 16S-23S ITS sequences to investigate seasonal and spatial changes in marine picocyanobacterial diversity in temperate coastal waters and to determine the ecological niches of these diverse lineages.

\section{MATERIALS AND METHODS}

\section{Study sites}

Two stations, Stn H6 and Stn I, were located in the ECS, and Stn D5 was located in the ES (Fig. 1). The ECS comprises a wide continental shelf shallower than $200 \mathrm{~m}$ that connects to the Yellow Sea (YS) and to the ES. The Kuroshio Current (KC), a western boundary current in the northwestern Pacific Ocean, is considered the major source of 2 branches, the Korea/Tsushima Warm Current (KTWC) and the Yel- low Sea Warm Current (YSWC) (Fig. 1). The former transports subtropical waters into the ES through the Korea/Tsushima Strait, while the latter flows into the YS (Ichikawa \& Beardsley 2002). In addition, the effect of the Changjiang River Diluted Water (CRDW) is intensified during summer due to heavy rainfall. Circulation in the ECS shows great seasonal variability, mainly due to the monsoon wind and discharge from Changjiang River. Stn I is located in the center of a shallow (water depth of ca. $50 \mathrm{~m}$ ) and mesotrophic shelf region and is seasonally affected by both CRDW and oligotrophic KC water. Stn H6 is located in a branch of the KC (Ichikawa \& Beardsley 2002) and is affected by this warm water mass almost year-round. The KTWC splits into 2 or 3 branches and affects the current system of the ES: the East Korean Warm Current, which flows northward along the east coast of Korea, and the Offshore Branch, which flows east-northeastward along the Japanese coast. Circulation in the southwestern ES is dominated by intraseasonal variability in warm and cold currents (Chang et al. 2004, Mitchell et al. 2005), and thus, Stn D5 is seasonally influenced by either warm or cold currents.

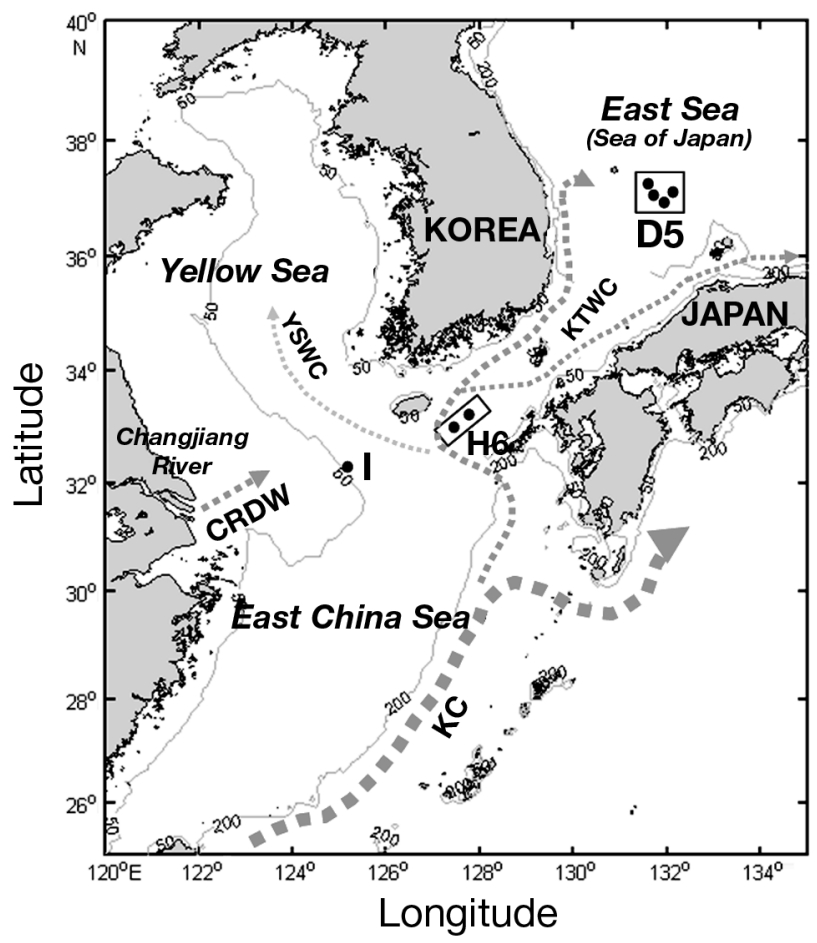

Fig. 1. The study area. Sampling sites at Stns H6 and D5 are located inside the boxes. Gray lines denote depth contour lines of 50 and $200 \mathrm{~m}$. Gray dotted lines represent the Kuroshio Current (KC), Korea/Tsushima Warm Current (KTWC), Yellow Sea Warm Current (YSWC) and Changjiang River Diluted Water (CRDW) in the area 


\section{Sampling}

Seawater samples were collected from the surface and the subsurface chlorophyll a ( $\mathrm{chl}$ a) maximum (SCM) depth using $10 \mathrm{l}$ Niskin bottles attached to a rosette sampler. If the development of a SCM was not observed, as may occur in the cold season, subsurface samples were collected at a depth of $20 \mathrm{~m}$. In total, 36 samples were analyzed in the present study (Table 1).

\section{Picocyanobacterial counts and environmental measurements}

Synechococcus and Prochlorococcus abundances were determined via a Beckman-Coulter Altra flow cytometer. Chl $a$, extracted with $90 \%$ acetone, was quantified using a fluorometer $(10 \mathrm{AU}$; Turner Designs; Parsons et al. 1984). Nutrient concentrations $\left(\mathrm{NH}_{4}, \mathrm{NO}_{3}+\mathrm{NO}_{2}\right.$ and $\left.\mathrm{PO}_{4}\right)$ were measured using a flow injection autoanalyzer (QuikChem $\mathrm{AE}_{\text {; }}$ Lachat Instruments) and standard colorimetric procedures (Strickland \& Parsons 1972). Temperature and salinity were measured using a conductivity, temperature and depth (CTD) sensor (SBE 9/11 plus; Sea Bird) mounted on a rosette sampler.

\section{DNA extraction}

Two-liter water samples were passed through a $0.2 \mu \mathrm{m}$ Supor ${ }^{\circledR}$ filter (Gelman Sciences), and the fil-

Table 1. Summary of environmental variables and picocyanobacterial abundances at the surface and subsurface chlorophyll maximum. Samples are grouped by season but not in chronological order. nd: not detected; na: not available

\begin{tabular}{|c|c|c|c|c|c|c|c|c|c|c|c|}
\hline Station & Season & Date & $\begin{array}{l}\text { Depth } \\
\text { (m) }\end{array}$ & $\begin{array}{l}\text { Temp } \\
\left({ }^{\circ} \mathrm{C}\right)\end{array}$ & Salinity & $\begin{array}{c}\mathrm{NO}_{2}+\mathrm{NO}_{3} \\
(\mu \mathrm{M})\end{array}$ & $\begin{array}{l}\mathrm{PO}_{4} \\
(\mu \mathrm{M})\end{array}$ & $\begin{array}{l}\mathrm{NH}_{4} \\
(\mu \mathrm{M})\end{array}$ & $\begin{array}{c}\text { Chl a } \\
\left(\mu g \mathrm{l}^{-1}\right)\end{array}$ & $\begin{array}{l}\text { Synechococcus } \\
\left(\times 10^{4} \text { cells ml }^{-1}\right)\end{array}$ & $\begin{array}{l}\text { Prochlorococcus } \\
\left(\times 10^{4} \text { cells } \mathrm{ml}^{-1}\right)\end{array}$ \\
\hline \multirow[t]{12}{*}{ H6 } & \multirow[t]{4}{*}{ Winter } & \multirow[t]{2}{*}{ Dec 2010} & 0 & 21.7 & 34.5 & 1.33 & 0.22 & na & 0.5 & 1.67 & nd \\
\hline & & & 20 & 21.8 & 34.5 & 1.31 & 0.19 & na & 0.5 & 3.23 & nd \\
\hline & & \multirow[t]{2}{*}{ Feb 2009} & 0 & 16.5 & 34.5 & 4.27 & 0.61 & 0.91 & 0.6 & 0.12 & nd \\
\hline & & & 30 & 16.5 & 34.5 & 4.56 & 0.51 & 0.95 & 0.6 & 0.08 & nd \\
\hline & \multirow[t]{4}{*}{ Spring } & \multirow[t]{2}{*}{ Apr 2008} & 0 & 18.0 & 34.6 & 0.16 & 0.15 & na & 0.4 & 0.53 & 0.42 \\
\hline & & & 25 & 16.5 & 34.6 & 0.11 & 0.09 & na & 1.6 & 0.44 & nd \\
\hline & & \multirow[t]{2}{*}{ Jun 2008} & 0 & 20.6 & 33.9 & 0.31 & 0.10 & 0.04 & 0.3 & 4.69 & nd \\
\hline & & & 30 & 20.5 & 33.9 & 0.42 & 0.12 & 0.09 & 0.3 & 4.69 & nd \\
\hline & \multirow[t]{2}{*}{ Summer } & \multirow[t]{2}{*}{ Aug 2008} & 0 & 30.0 & 31.5 & nd & nd & nd & 0.2 & 4.72 & 1.80 \\
\hline & & & 37 & 20.9 & 33.8 & 10.68 & 0.73 & nd & 0.9 & 2.77 & nd \\
\hline & \multirow[t]{2}{*}{ Autumn } & \multirow[t]{2}{*}{ Sep 2011} & 0 & 26.7 & 34.0 & 0.05 & 0.07 & na & 0.2 & 5.50 & nd \\
\hline & & & 58 & 24.3 & 34.2 & 2.34 & 0.26 & na & 0.3 & 0.41 & 2.26 \\
\hline \multirow[t]{12}{*}{ I } & \multirow[t]{4}{*}{ Winter } & \multirow[t]{2}{*}{ Dec 2010} & 0 & 16.9 & 32.0 & 11.23 & 0.37 & na & 0.8 & 1.48 & nd \\
\hline & & & 20 & 16.9 & 32.0 & 10.59 & 0.37 & na & 0.8 & 3.40 & nd \\
\hline & & \multirow[t]{2}{*}{ Feb 2009} & 0 & 10.0 & 32.4 & 9.57 & 0.72 & 1.28 & 0.4 & 0.07 & nd \\
\hline & & & 20 & 9.9 & 32.4 & 10.12 & 0.76 & 1.22 & 0.4 & 0.09 & nd \\
\hline & \multirow[t]{4}{*}{ Spring } & \multirow[t]{2}{*}{ Apr 2008} & 0 & 11.6 & 32.5 & 3.70 & 0.23 & na & 1.7 & 0.62 & nd \\
\hline & & & 20 & 10.9 & 32.6 & 6.13 & 0.32 & na & 0.4 & 0.31 & nd \\
\hline & & \multirow[t]{2}{*}{ Jun 2008} & 0 & 18.0 & 32.5 & 0.24 & 0.09 & 0.04 & 0.8 & 16.75 & nd \\
\hline & & & 10 & 15.5 & 32.6 & 1.86 & 0.18 & 0.05 & 1.0 & 8.23 & nd \\
\hline & \multirow[t]{2}{*}{ Summer } & \multirow[t]{2}{*}{ Aug 2008} & 0 & 27.8 & 29.5 & 0.66 & 0.02 & 0.02 & 1.1 & 3.61 & nd \\
\hline & & & 15 & 24.7 & 29.9 & 1.70 & 0.02 & 0.02 & 1.4 & 11.69 & nd \\
\hline & \multirow[t]{2}{*}{ Autumn } & \multirow[t]{2}{*}{ Sep 2011} & 0 & 23.4 & 32.1 & 0.56 & 0.05 & na & 0.7 & 2.46 & nd \\
\hline & & & 20 & 23.6 & 32.2 & 0.49 & 0.06 & na & 0.7 & 2.77 & nd \\
\hline \multirow[t]{12}{*}{ D5 } & \multirow[t]{4}{*}{ Winter } & \multirow[t]{2}{*}{ Dec 2007} & 0 & 14.1 & 33.8 & 3.10 & 0.16 & 0.61 & 1.0 & 1.86 & nd \\
\hline & & & 20 & 14.1 & 33.8 & 3.21 & 0.31 & 0.55 & 1.0 & 1.65 & nd \\
\hline & & Feb 2008 & 0 & 10.9 & 34.3 & 4.76 & 0.42 & 0.59 & 1.8 & 0.20 & nd \\
\hline & & & 30 & 11.0 & 34.3 & 4.88 & 0.36 & 0.64 & 1.5 & 0.19 & nd \\
\hline & Spring & Mar 2008 & 0 & 10.6 & 34.3 & 3.03 & 0.32 & 0.71 & 1.0 & 0.31 & nd \\
\hline & & & 50 & 10.5 & 34.3 & 3.94 & 0.31 & 0.62 & 1.1 & 0.38 & nd \\
\hline & & Apr 2006 & 0 & 10.7 & 34.4 & 4.25 & 0.38 & na & 0.2 & 0.02 & nd \\
\hline & & & 50 & 9.1 & 34.3 & 5.20 & 0.49 & na & 0.4 & 0.04 & nd \\
\hline & Summer & Aug 2008 & 0 & 26.7 & 33.3 & 0.27 & 0.09 & 0.76 & 0.1 & 2.05 & 1.49 \\
\hline & & & 50 & 15.3 & 34.4 & 0.23 & 0.16 & 0.29 & 0.8 & 2.24 & 0.06 \\
\hline & Autumn & Oct 2008 & 0 & 22.7 & 33.3 & 0.08 & 0.27 & na & 0.2 & 4.12 & 4.51 \\
\hline & & & 34 & 17.8 & 34.2 & 2.04 & 0.29 & na & 0.4 & 1.12 & 1.27 \\
\hline
\end{tabular}


ters were stored at $-80^{\circ} \mathrm{C}$ after the addition of $1 \mathrm{ml}$ STE buffer $(100 \mathrm{mM} \mathrm{NaCl}, 10 \mathrm{mM}$ Tris-HCl and 1 mM EDTA, pH 8.0) for DNA analyses. To extract DNA, the filters were cut into small pieces with sterile scissors and, with the remaining storage buffer, were placed in $50 \mathrm{ml}$ sterilized conical tubes. After adding $2 \mathrm{ml}$ of fresh STE buffer, the cells were lysed using lysozyme and proteinase $K$, and then DNA was extracted using phenol/chloroform/isoamyl alcohol according to Somerville et al. (1989).

\section{Pyrosequencing of ITS sequences}

To elucidate picocyanobacterial ITS sequence diversity, barcoded amplicon pyrosequencing using the GS-FLX Titanium system was conducted. To amplify partial picocyanobacterial ITS sequences, barcoded primers were used. The barcoded primers consisted of adapter A (forward) or B (reverse) + Key (TCAG) + barcode (10 bp oligonucleotide, forward only) + picocyanobacteria-specific primers. The ITS-af (5'-GGA TCA CCT CCT AAC AGG GAG-3') and ITS-ar (5'GGA CCT CAC CCT TAT CAG GG-3') primers were used as specific primers (Lavin et al. 2008). The ITS-af and ITS-ar primers showed perfect matches to $99 \%$ of the 2389 picocyanobacterial ITS sequences obtained from cultures and clone libraries, indicating high specificity to picocyanobacteria. The fused primer set produced amplicons of ca. 250 to $330 \mathrm{bp}$.

One to $10 \mathrm{ng}$ of template DNA was added to the PCR reaction (total $50 \mu \mathrm{l}$ ), which contained Ex Taq buffer (Takara Bio), $0.2 \mathrm{mM}$ of each dNTP, $0.5 \mu \mathrm{M}$ of each primer and $2 \mathrm{U}$ of Ex Taq (Takara Bio). PCR amplification was conducted according to the following cycle parameters: an initial denaturation step ( $5 \mathrm{~min}, 94^{\circ} \mathrm{C}$ ) was followed by 35 cycles consisting of denaturation $\left(45 \mathrm{~s}, 94^{\circ} \mathrm{C}\right)$, annealing $\left(45 \mathrm{~s}, 52^{\circ} \mathrm{C}\right)$ and extension $\left(1.5 \mathrm{~min}, 72^{\circ} \mathrm{C}\right)$ steps and a final $10 \mathrm{~min}$ extension step at $72^{\circ} \mathrm{C}$. The size of the PCR products was confirmed via agarose gel electrophoresis. When PCR failed to amplify the DNA or produced a faint band, nested PCR was applied (see Table 2). In this case, the first PCR was conducted using the 16S$1247 \mathrm{~F}$ and $23 \mathrm{~S}-241 \mathrm{R}$ primers under the suggested PCR conditions (Rocap et al. 2002). Each PCR product was quantified on agarose gels using DNA QuantLadders (Lonza Rockland). Equal quantities of each PCR product were pooled and then purified using the AccuPrep PCR purification kit (Bioneer). After resolution on a $2 \%$ agarose gel, the region between 200 and 400 bp was excised, and DNA was extracted using a Qiagen Gel Extraction kit (Qiagen).
Pyrosequencing (on a 1/8 PicoTiterPlate) of PCR products was performed at Macrogen. Sequence reads from the present study were submitted to the NCBI sequence read archive (www.ncbi.nlm.nih. gov/Traces/sra; accession number SRA089070).

\section{Database for pyrosequencing data analysis}

For pyrosequencing analysis, a database was constructed using ITS sequences from cultures and clone libraries from 14 previous studies (Rocap et al. 2002, Ahlgren \& Rocap 2006, Chen et al. 2006, Haverkamp et al. 2008, 2009, Choi \& Noh 2009, Jing et al. 2009a,b, Cai et al. 2010, Lavin et al. 2010, Mella-Flores et al. 2011, Huang et al. 2012, Jing \& Liu 2012, Mazard et al. 2012) as well as unpublished data (GenBank accession nos. HQ336805-HQ336939; D. H. Choi \& J. H. Noh unpubl. data). The sequences were aligned using the MAFFT program (v. 7; Katoh \& Standley 2013) with the FFT-NS-I strategy. After manual correction, the alignment was imported into the ARB program (Ludwig et al. 2004). A neighbor-joining (NJ) tree for full-length ITS sequences was built; however, because the highly conserved tRNA region was not informative in phylogenetic analysis, the tRNA sequence was removed. The robustness of nodes was examined using the bootstrap method. Using the tree, the sequences were classified according to previous clade designations (Rocap et al. 2002, Ahlgren \& Rocap 2006, Chen et al. 2006, Choi \& Noh 2009, Mella-Flores et al. 2011, Huang et al. 2012). Clades not clearly resolved in the bootstrap tree and clades with relatively high similarities between closest clades were grouped together (Fig. 2). In these cases, the group was assigned the earliest published clade name. Finally, the database contained 1651 ITS sequences belonging to Synechococcus subcluster (SC) 5.1 (814 sequences), Synechococcus SC5.2 (29 sequences belonging to marine clades CB4 and CB5), Synechococcus SC5.3 (76 sequences) and Prochlorococcus (732 sequences).

Next, we annotated the sequences with 4-rank taxonomic information (Cyanobacteria; Synechococcus or Prochlorococcus; Synechococcus subclusters or Prochlorococcus high-light adapted [HL]/low-light adapted [LL]; clades). For the reference alignment, the region between the forward primer and tRNA ${ }^{\text {Ile }}$ was cropped from the full-length alignment used in the phylogenetic analysis above. In addition, a reference sequence file and its corresponding taxonomic file (to be used for clade-assignment of pyrosequencing reads) were exported from the ARB database. 


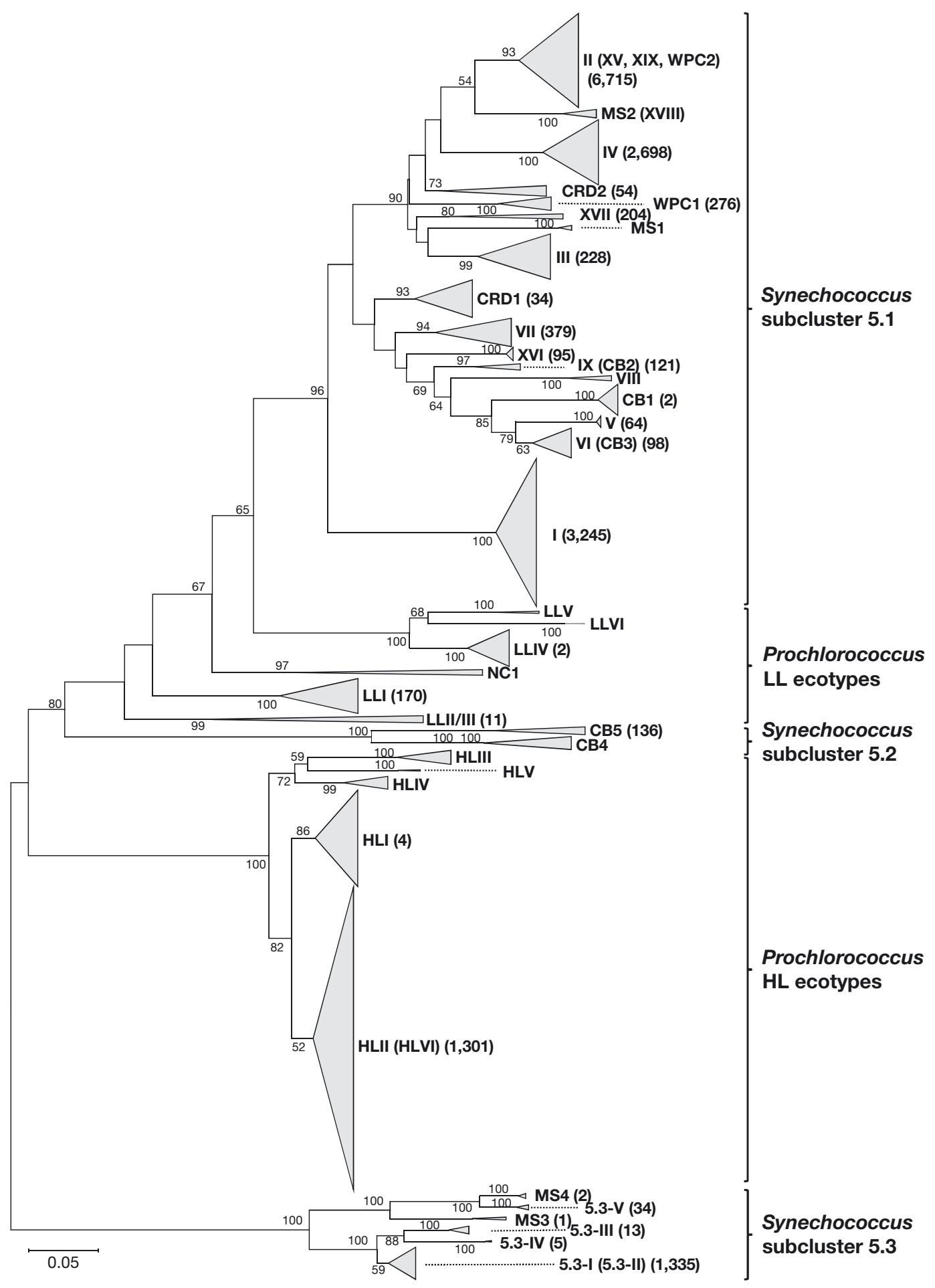

Fig. 2. Compressed neighbor-joining tree based on 1220 positions of 16S-23S rDNA internal transcribed sequences showing the phylogenetic relationships among Synechococcus and Prochlorococcus genotypes. In total, 1619 sequences were used to construct the tree. Only bootstrap values $>60 \%$ from 100 replicates are shown. Clade names are shown on the right of compressed branches. Clade names in parentheses represent clades grouped together with 1 representative clade on the basis of robustness of nodes or distances among closest clades. The numbers in parentheses following the clade name represent the total number of pyrosequencing reads belonging to each clade. The thickness and length of triangles are proportional to the number of sequences and distances among sequences, respectively. LL: low-light adapted; HL: high-light adapted. Scale bar = 


\section{Analysis of pyrosequencing data}

Pyrosequencing data were mainly analyzed using the Mothur software (Schloss et al. 2009). To remove reads associated with errors, raw reads were filtered by allowing only those with a perfect match to barcode and forward primer sequences. The maximum allowed homopolymer length was $6 \mathrm{bp}$. Reads with an initial noisy signal (flow intensity: 0.5 to 0.7 ) before 150 flows were removed and flows beyond 350 were ignored. Then, flowgram data were grouped by samples based on their barcodes. The filtered reads were de-noised using 'shhh.flows' command, which is the Mothur-based re-implementation of PyroNoise (Quince et al. 2011). Then, the 'chimera.perseus' command was used to identify chimeric sequences. The remaining reads were aligned using the Needleman algorithm and the reference alignment. Subsequently, reads showing similarities $<90 \%$ to the reference sequences were screened to remove nonspecifically amplified reads. In addition, short reads not covering the full alignment were removed to avoid inconsistent classification by size difference. Using the 'pre.cluster' command (with the option of diffs $=4$ ), the aligned reads were clustered to remove sequences that were likely due to pyrosequencing errors. Then, chimeric sequences were also removed using the 'chimera. uchime' command. The remaining reads were classified to each corresponding clade by means of the 'classify.seqs' command ( $k$-nearest neighbor approach with an option of $k=1$ ) using the reference sequence and its taxonomy files.

\section{Statistical analyses}

To view relationships among samples based on differences in clade diversity, a principal coordinates analysis (PCoA) was conducted using the FastUniFrac Web application based on NJ trees (Hamady et al. 2010). Samples were clustered based on the normalized weighted UniFrac distance. Canonical correspondence analysis (CCA) was performed using Canoco for Windows (v. 4.51) to clarify the factors controlling picocyanobacterial clades distribution. Explanatory variables (temperature, salinity, nitrate + nitrite, phosphate, chl a and Synechococcus abundances) were $\log (\mathrm{n}+1)$-transformed, and response variables (clade \%) were square root-transformed prior to analysis. The CCA model was produced with forward selection via Monte Carlo permutation significance tests $(\mathrm{p}<0.05)$.
To determine the depth of coverage in each sample, Good's coverage was calculated using Mothur software (Schloss et al. 2009).

\section{RESULTS}

\section{Physicochemical characteristics of samples}

At all stations, seawater temperature showed a seasonal pattern typical of temperate waters (Table 1). However, the ranges of values and vertical variation differed among stations. At Stn H6, the surface temperature was $\sim 8^{\circ} \mathrm{C}$ higher during the winter and $3^{\circ} \mathrm{C}$ higher during the summer compared to other stations (Table 1). Surface temperatures were similar at Stns I and D5. Subsurface water temperatures showed large differences among stations (Table 1).

At Stn D5, salinity varied within a narrow range of 33.3 to 34.4 (Table 1). However, salinity in the ECS was lower and more variable than that observed in the ES, mainly due to runoff from the Changjiang River. This runoff appeared to influence Stn H6 in summer, resulting in a decrease in surface salinity from $\sim 33.9$ in June to 31.5 in August. In contrast, salinity at Stn I was consistently $<32.6$, indicating the persistent influence of low salinity water from the Changjiang River.

The sum of nitrate and nitrite concentrations ranged from undetectable to $10.7 \mu \mathrm{M}$ and tended to be higher at Stn I than at any other station (Table 1). During the winter, relatively high nutrient concentrations (3.1 to $10.1 \mu \mathrm{M})$ were observed at the surface due to vertical mixing. In the summer and autumn, nutrient concentrations were low at the surface but high at the subsurface due to thermal stratification. Phosphate concentrations showed similar seasonal trends as the sum of nitrate and nitrite, but the concentrations were more than an order of magnitude lower.

\section{Chl $a$ and picocyanobacterial abundances}

Chl a concentrations varied from 0.1 to $1.8 \mu \mathrm{g} \mathrm{l}^{-1}$ during the present study, and overall ranges were similar at the 3 stations (Table 1). At Stn $\mathrm{H6}$, which is influenced by oligotrophic KC water, chl a was lower than at Stn I during seasons in which vertical mixing was restricted due to thermal stratification. During summer, relatively high chl a values were observed at Stn I due to the inflow of the nutrient-rich CRDW (Table 1). The wide range in chl a concentrations 
indicates that these regions shift seasonally from oligotrophic to mesotrophic states.

Synechococcus abundances varied by up to 3 orders of magnitude across seasons (Table 1). In February, Synechococcus abundance was extremely low, ranging from $0.07 \times 10^{4}$ to $0.20 \times 10^{4} \mathrm{cells} \mathrm{ml}^{-1}$; the abundance then greatly increased and peaked between late spring and autumn (Table 1). The seasonal Synechococcus abundance patterns were similar at all 3 stations, but abundance was higher at Stn I during late spring and summer. At low temperatures, Synechococcus abundance increased with seawater temperature (Fig. 3). However, at ca. $20^{\circ} \mathrm{C}$, Synechococcus abundances tended toward saturation, although their compositions changed dynamically (see section 'Seasonal and spatial compositions of picocyanobacterial assemblages').

When using flow cytometry, Prochlorococcus was detected in samples collected during summer and autumn but not in most other seasons (Table 1). However, failure to detect via flow cytometry does not indicate the total absence of Prochlorococcus given that Prochlorococcus sequences were successfully retrieved via pyrosequencing in several samples (Table 2). This discrepancy seems to have been due to a methodological failure, namely low abundance and dim fluorescence, as reported in other studies (Jacquet et al. 1998, Mella-Flores et al. 2011).

\section{Characteristics of the pyrosequencing run}

In total, 20874 reads passed our trimming and screening procedures (barcode and primer matches and amplicon size). Additionally, 3556 reads were removed through the chimera screening and alignment procedures. Then, the remaining 17227 reads were classified into 27 distinct Synechococcus and Prochlorococcus clades (Table 2). To determine whether the classification was reliable, a phylogenetic analysis using the aligned reads and 'add sequences into existing tree' method of the ARB program was also conducted. Between the 2 methods, at-odds or incorrect classifications were noted for only 37 sequences $(0.2 \%$ of the total reads, data not shown), suggesting that clade classification using the Mothur pipeline is reliable. The read numbers per sample ranged from 105 to 1486, showing large variation. However, Good's coverage index estimated at a minimum read number of 105 was $>97 \%$ for all samples (data not shown), indicating that sequence numbers were sufficient to assess picocyanobacterial diversity.

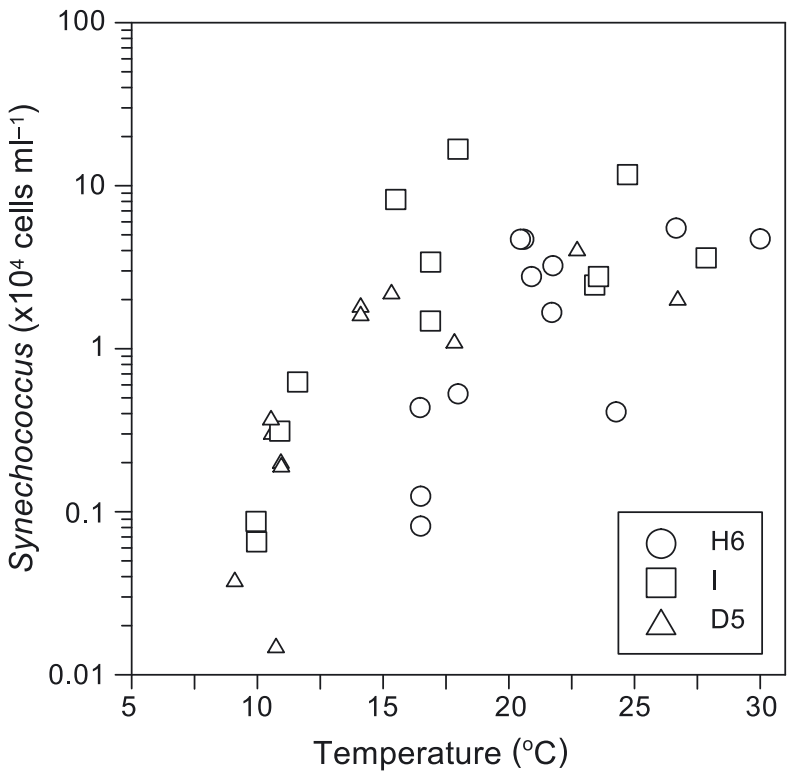

Fig. 3. Relationship between water temperature and Synechococcus abundances in the present study at 3 stations (H6 and I in the East China Sea and D5 in the East Seal/Sea of Japan)

\section{Seasonal and spatial compositions of picocyanobacterial assemblages}

In the ECS and ES, diverse Synechococcus and Prochlorococcus lineages appeared in time and space (Table 2). The number of clades found in each sample varied between 2 and 19, indicating large variation in picocyanobacterial diversity among samples. At Stns I and D5, markedly fewer lineages (2 to 6 clades) were observed during the cold season from late winter to late spring; however, the number increased in warmer water.

Thirteen of 17 clades belonging to Synechococcus SC5.1 were retrieved at fractions greater than $1 \%$ in at least 1 sample. At Stn D5, located in middle of the ES and thus far from the direct effects of freshwater and warm $\mathrm{KC}$ water, we observed apparently distinct picocyanobacterial compositions across seasons. At low seawater temperatures $\left(\sim 10^{\circ} \mathrm{C}\right)$, both Synechococcus Clades I and IV composed the greater part of all picocyanobacteria (82 to $100 \%$ ). However, in surface water in the summer and autumn $\left(23\right.$ to $\left.27^{\circ} \mathrm{C}\right)$, Clade II comprised the dominant picocyanobacteria (50 to $62 \%$ ), followed by the Prochlorococcus HLII ecotype (23 to $39 \%$ ). However, Clades I and IV remained the dominant lineages at SCM depth in August and October, when seawater temperatures were consistently low due to thermal stratification (Table 1). At Stn I, seasonal picocyanobacterial compositions were similar compared to those at Stn D5. However, sev- 


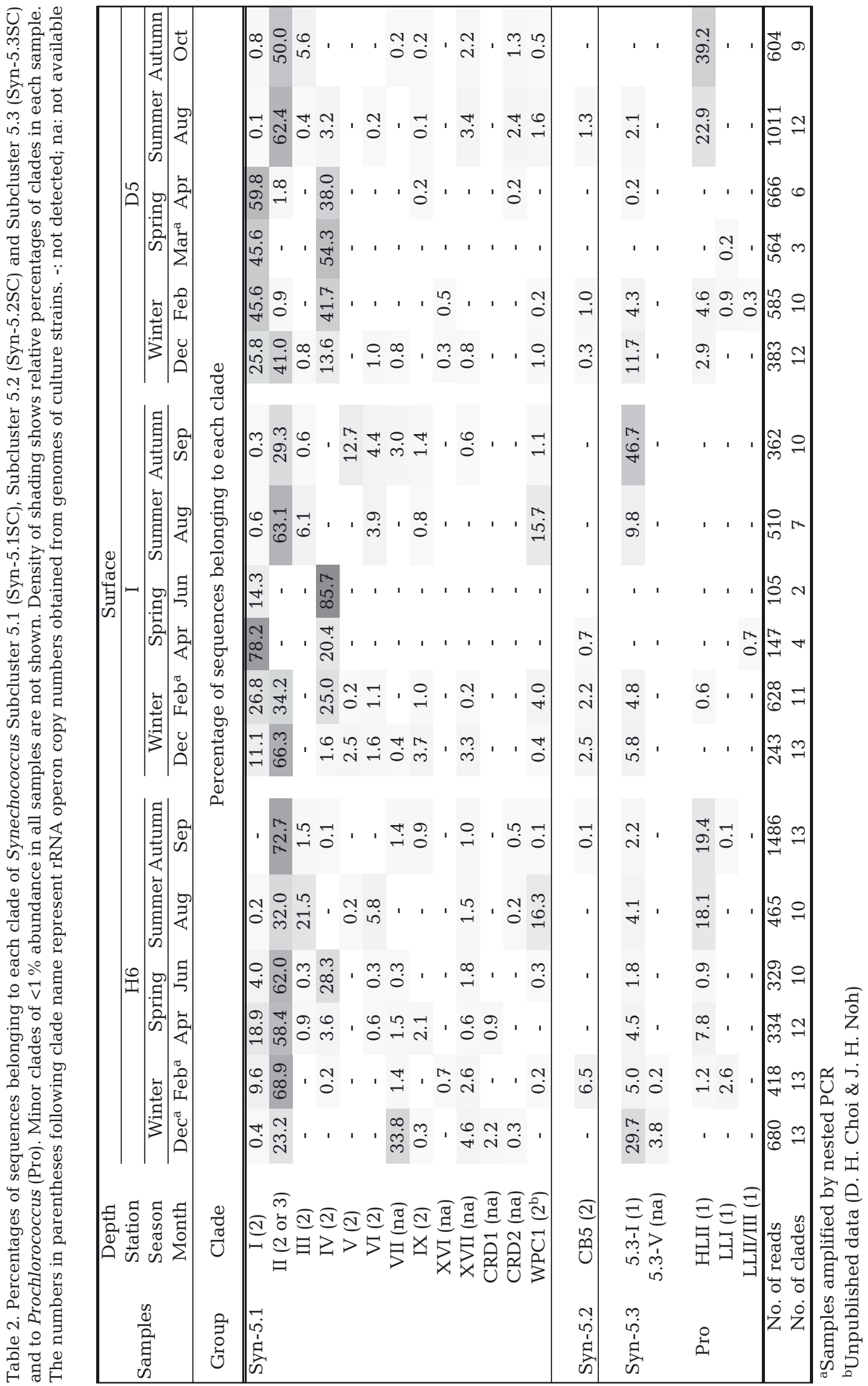




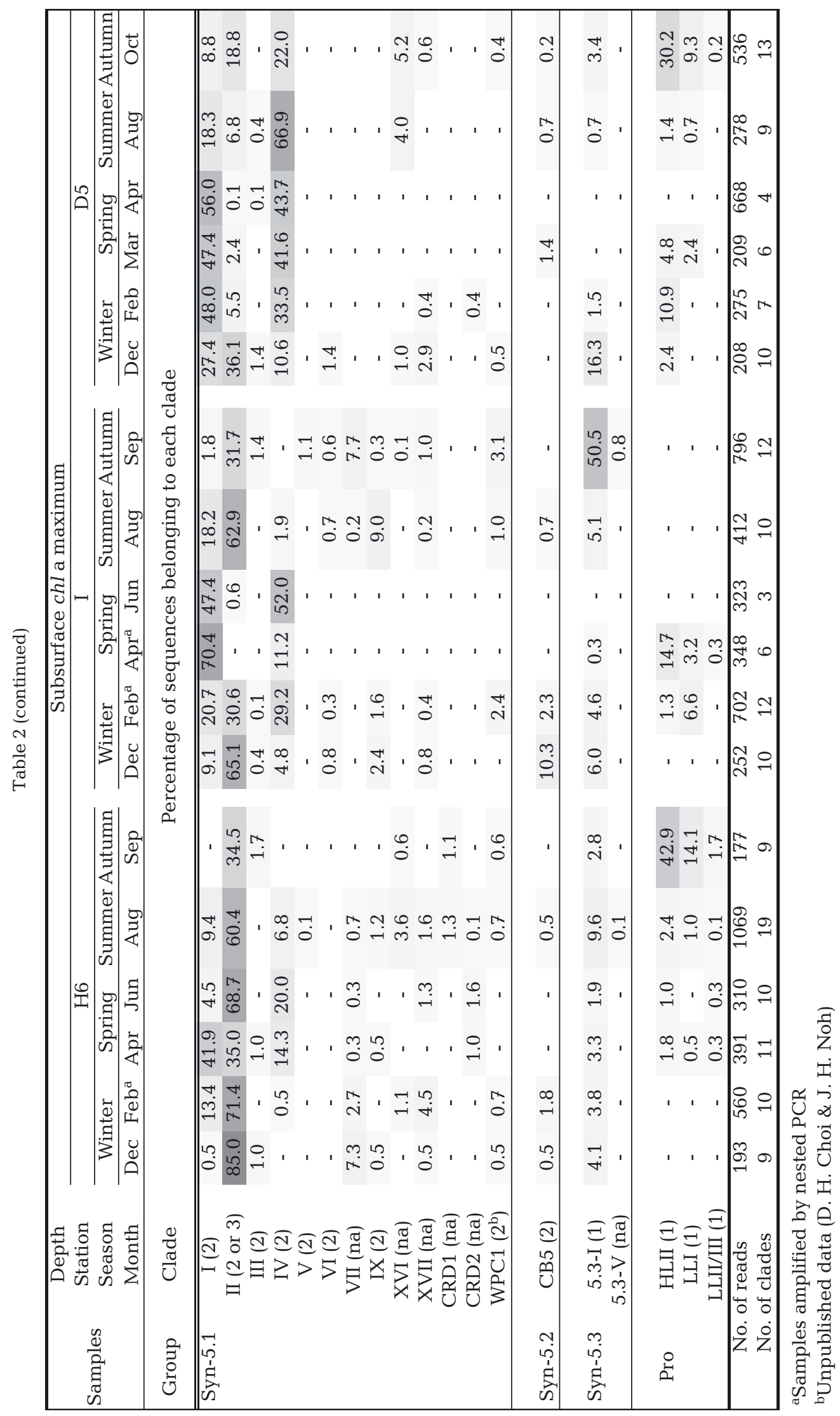


eral differences are worth noting. At both the surface and SCM depths in autumn, Clade 5.3-I was dominant, comprising $\sim 50 \%$ of the picocyanobacterial community. In addition, Clades V and WPC1 showed relatively high contributions ( $15 \%$ each) at the surface in September and August, respectively. Furthermore, no Prochlorococcus sequence was retrieved from samples collected during the summer and autumn. In contrast to all other stations, Synechococcus Clade II was the dominant picocyanobacterium at Stn H6 in all seasons (Table 2). Although Clade I and IV sequences were also observed in late winter and spring samples, their contributions were relatively low compared to that of Clade II at Stn H6.

Clade CB5 belonging to Synechococcus SC5.2 ranged from undetectable to $10.3 \%$ of the sequences, and its overall sequence fraction tended to increase with decreasing temperature. Among the 6 clades in

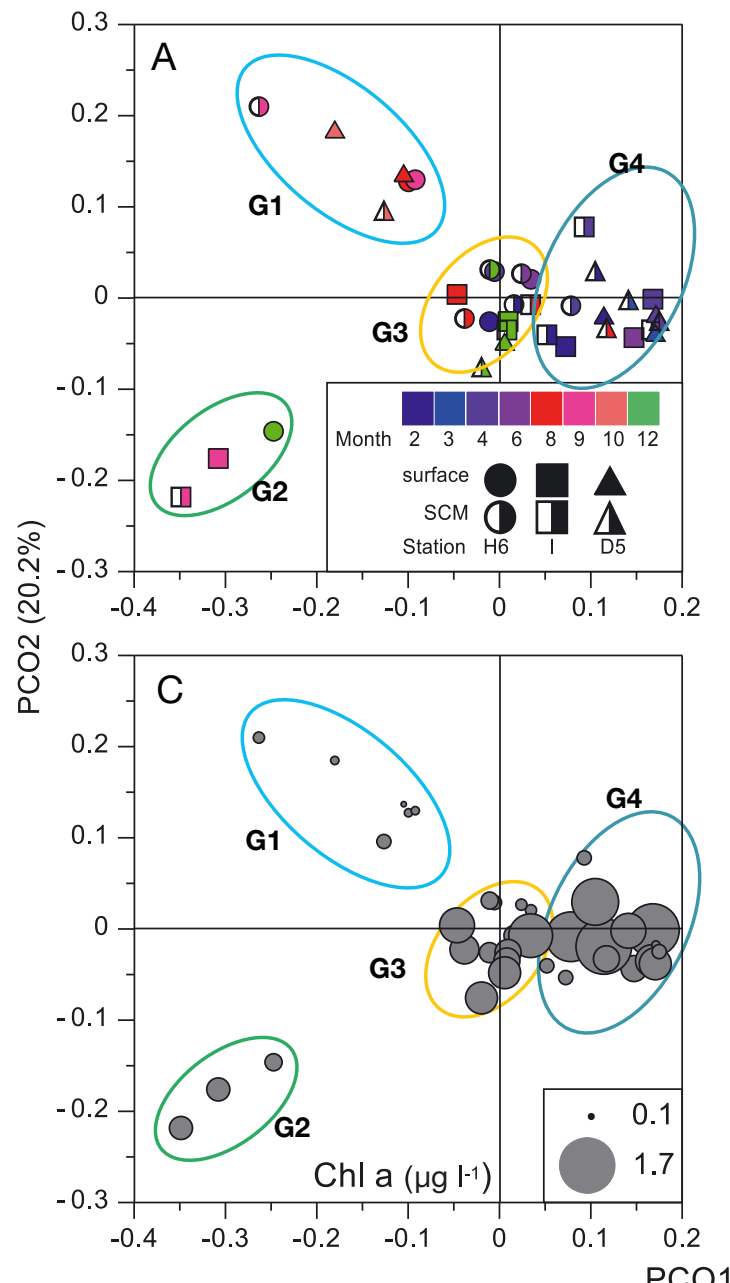

Synechococcus SC5.3, clade 5.3-I was dominant, comprising up to $46.7 \%$ of the picocyanobacterial sequences. Prochlorococcus sequences were found in most samples from Stns H6 and D5 (Table 2). At Stn I, however, Prochlorococcus sequences were retrieved only in February and March. Prochlorococcus Clade HLII was dominant in both surface and SCM samples. The Prochlorococcus LLI ecotype was detected more frequently at the SCM depth than at the surface and appeared to make up a greater fraction of the total sequences in deeper water.

\section{Relationships between picocyanobacterial community distribution and environmental factors}

Based on PCoA, the greatest part of the observed sample variation $(82.9 \%)$ could be accounted for by
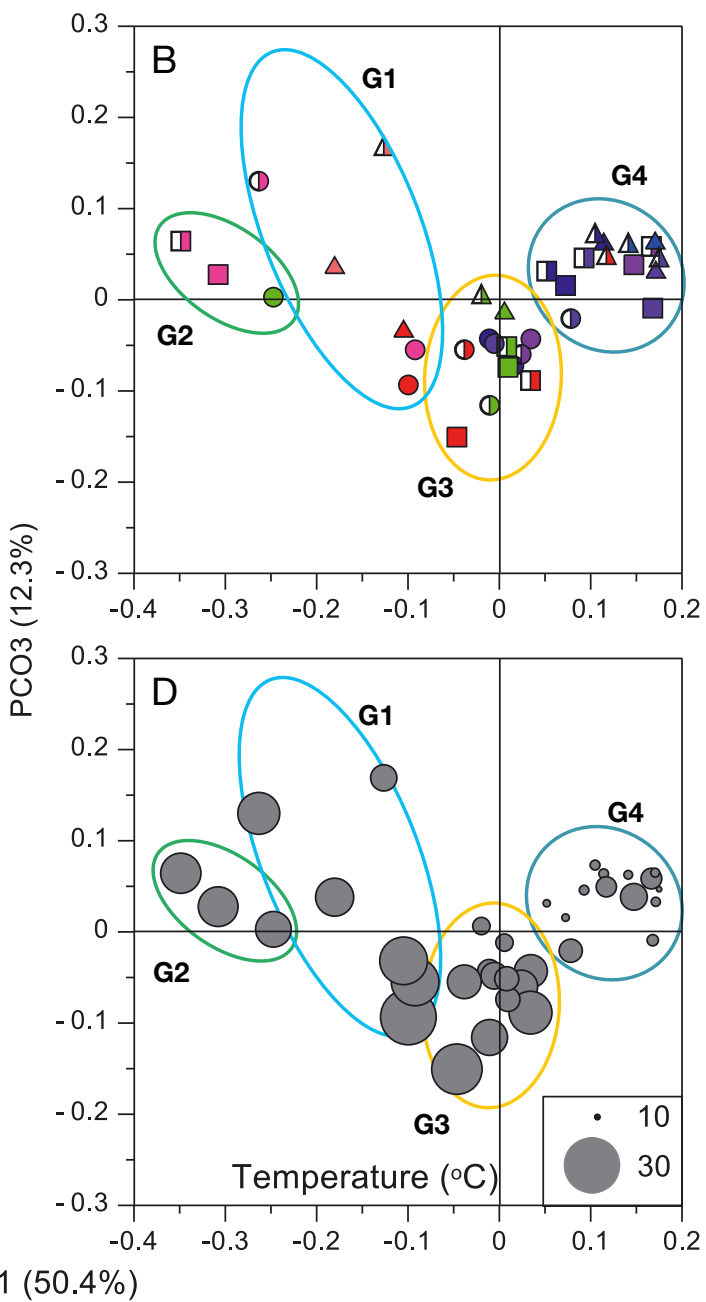

Fig. 4. Principal coordinates analysis of samples with the normalized weighted UniFrac. Plots of (A) the first 2 principal axes and (B) the first vs. third axes are shown. Plots (C) and (D) are the same plots as (A) and (B), respectively, but represent (C) chl a concentration and (D) temperature for each sample. The circles represent 4 groups classified on the basis of clustering patterns of samples 
the first 3 principal components, and the samples could be divided into 4 groups (Fig. 4). Group G1 was made up of summer and autumn samples typified by high temperatures and low chl a levels (Fig. 4C,D). In these G1 samples, Clade II (19 to $73 \%$ ) and Prochlorococcus HLII members (18 to $43 \%$ ) were dominant, indicating the oligotrophic state of these samples. In a sample from the G1 group, Clades III and WPC1 showed their highest percentages, although these represented a low overall contribution (22 and 16\%, respectively). In samples clustered within Group G2 (Fig. 4), Synechococcus 5.3-I was dominant (30 to $51 \%$ ) over Clade II (23 to $32 \%$ ). Compared to G1, these samples were typified by slightly lower temperatures (ca. $23^{\circ} \mathrm{C}$ ) but relatively higher chl a levels (Figs. 4C,D). Another striking difference of G2 samples was the total lack of Prochlorococcus sequences. Clade VII was frequently found at Stn H6 influenced by oligotrophic KC water, and the highest contribution (34\%) was observed in the sample belonging to Group G2 (Table 2, Fig. 4). Group G3 primarily included samples with temperatures between $14^{\circ} \mathrm{C}$ and $21^{\circ} \mathrm{C}$. In these samples, Clade II was dominant (36 to $67 \%$ ), although Clades I and IV also made up a considerable fraction of the sequences ( 7 to $38 \%$ ). Thus, these ecologically contrasting clades were able to co-exist at intermediate water temperatures. Samples clustering in Group G4 exhibited the lowest temperatures $\left(9\right.$ to $\left.18^{\circ} \mathrm{C}\right)$. Samples obtained at Stns I and D5 during the winter to spring and samples from

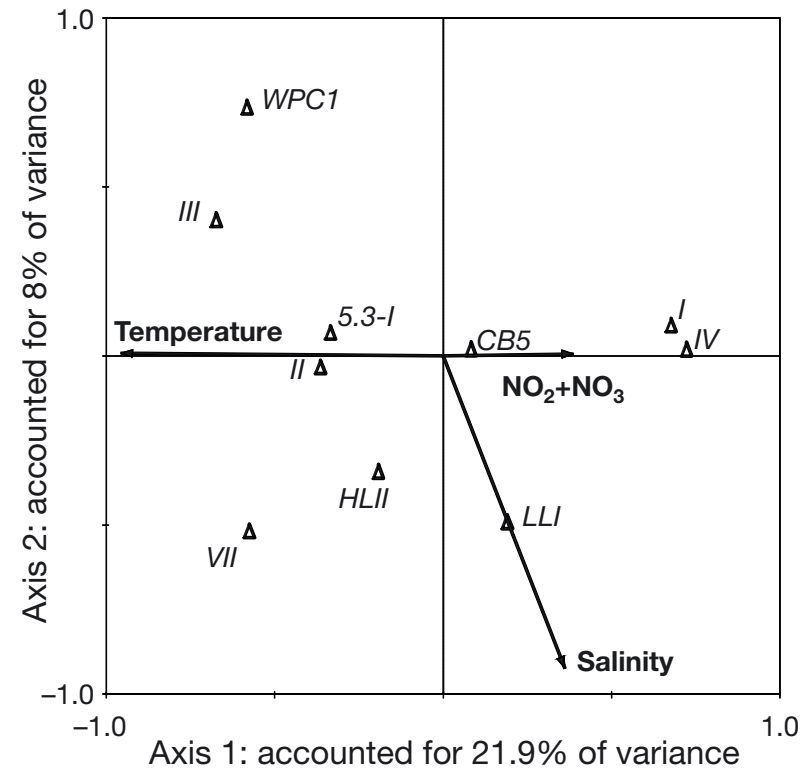

Fig. 5. CCA ordination plot for the first 2 CCA dimensions of the relationship between picocyanobacterial composition and environmental parameters. Only clades with $>10 \%$ in at least 1 sample are shown. See Fig. 2 for clade identifications
SCM depth at Stn D5 in summer were mainly made up of Clades I and IV.

The CCA analysis also showed that the distribution of picocyanobacterial lineages was primarily related to temperature, $\mathrm{NO}_{3}+\mathrm{NO}_{2}$ and salinity (Fig. 5). As noted above, Clades I and IV were situated on the right side of the biplot, indicating their preference for cold and relatively eutrophic waters. In contrast, the remaining clades were positioned opposite to Clades I and IV, suggesting that these Synechococcus and Prochlorococcus lineages favor warm and relatively lower nutrient conditions. However, the dynamic changes observed in the Synechococcus community, especially during the summer, suggest that individual Synechococcus lineages may respond to narrow ranges of temperature and nutrient concentrations and thus may have specific ecological niches (Tai et al. 2011).

\section{DISCUSSION}

\section{Methodological considerations}

To understand picocyanobacterial diversity in marine environments, clone libraries and specific probe/ primer sequence-based quantitative approaches (southern hybridization or qPCR) have been widely used. However, analyzing clone libraries from tens of samples and performing qPCR for a multiple sets of primers or probes is laborious and expensive. In our experience, a single run of amplicon pyrosequencing using $>100$ barcodes on a 1/8 PicoTiter Plate could produce $>600$ high-quality reads per sample on the average (data not shown). Furthermore, only approximately a hundredth of this read number would be sufficient to study picocyanobacterial diversity at the clade level (see 'Results'). Thus, pyrosequencing is an appropriate tool for studying picocyanobacterial diversity in large numbers of samples due to its advantages in terms of time, cost and the quantity of data generated. However, note that pyrosequencing generates qualitative output and thus requires prior knowledge of the rRNA operon copy number and cell abundances to arrive at a quantitative estimation. To date, genomes have been sequenced for strains belonging to diverse Synechococcus and Prochlorococcus clades (see IMG-ER database; Markowitz et al. 2009). The rRNA operon copy numbers are either 1 or 2 in most strains (see Table 2). By applying these values to each clade or overall group means, the number of picocyanobacteria belonging to each clade can be approximated from Synechococcus and Prochlorococcus abundances without extreme bias. 


\section{Seasonal pattern of picocyanobacterial abundances}

In the ECS and ES, Synechococcus abundances tended to increase markedly at temperatures below $20^{\circ} \mathrm{C}$ (Fig. 3), at which point saturation was reached. At Stn I, maximal Synechococcus abundances were similar to or slightly lower than those found at the Scripps pier over a 3 yr observation period (Tai \& Palenik 2009). At the Scripps pier, a Synechococcus bloom was characterized by the codominance of Clades I and IV (Tai \& Palenik 2009). Likewise, at Stn I in June with rapid increases in abundance, Clades I and IV exhibited dominance (Tables 1 \& 2). Contrary to the observed codominance of Clades I and IV throughout the year at Scripps pier, however, the dominant Synechococcus was Clade II in summer in the present study. This dramatic change seems to be related to high temperatures (ca. $28^{\circ} \mathrm{C}$ ) observed in August. In the subtropical Gulf of Aqaba in the Red Sea (Post et al. 2011), the surface of subtropical northwestern Pacific Ocean (Choi et al. 2011) and in coastal/continental shelf zones in subtropical/ tropical areas (Zwirglmaier et al. 2008), Clade II was dominant, suggesting that this lineage is highly competitive in warm waters. Similarly dramatic changes in Synechococcus diversity during periods of high abundance were also observed in surface waters of the ES (Table 2). Therefore, increases in Synechococcus abundance in temperate waters were attributable to Clades I and IV at intermediate temperature $\left(\sim 20^{\circ} \mathrm{C}\right)$, whereas at higher temperatures, changes in abundance were due to the warm-water-adapted clades.

At Stn H6 in February, Synechococcus abundances were 1 order of magnitude lower than those found at other stations at temperatures comparable to that of Stn H6 (Table 1). Stn H6 was likely to be affected by a branch of warm $\mathrm{KC}$, and when the water temperatures decreased to $16^{\circ} \mathrm{C}$ in winter, the temperature would limit the growth of the dominant warm wateradapted Clade II Synechococcus (ca. 70\%) (Table 2). Further, advection of cold-water-adapted Clades I and IV to Stn H6 through the shelf area would not be large in winter. Thus, the low abundances at Stn H6 seem to be related to both temperature and Synechococcus composition. In addition, the low abundances may have been due to limited light intensity as a result of active vertical mixing, considering that recent mesocosm experiments have shown that light plays an important role in the initiation of spring blooms (Sommer \& Lengfellner 2008). Thus, in winter, Synechococcus abundances may be limited by temperature and light intensity.
Prochlorococcus is predominant in oligotrophic and tropical open ocean waters between $40^{\circ} \mathrm{N}$ and $40^{\circ} \mathrm{S}$ (Partensky et al. 1999). However, their distribution is suppressed in coastal areas and in upwelling waters (Partensky et al. 1999, Liu et al. 2004, Johnson et al. 2006). In the present study, we observed high summer and autumn abundances for Prochlorococcus $\left(4.5 \times 10^{4}\right.$ cells ml $^{-1}$; Table 1$)$ in the central ES and the northeastern ECS influenced by the KC. In contrast, Prochlorococcus was not detected at Stn I. Thus, our work suggests that Prochlorococcus advected from the oligotrophic open ocean may continue to grow in marginal seas as long as conditions remain warm and oligotrophic; however, their growth appears to be inhibited in shallow shelf waters heavily influenced by the CRDW. Unexpectedly, Prochlorococcus sequences were found in several winter samples with low temperatures of ca. $10^{\circ} \mathrm{C}$ (Table 2). Because low temperatures have adverse effects on the growth of Prochlorococcus (Moore et al. 1995), its presence in winter samples was more likely due to advection from adjacent $\mathrm{KC}$ waters. Because Synechococcus abundances are low at that time, most likely due to light limitation and low temperatures, the advected Prochlorococcus would have a relatively high contribution to picocyanobacterial abundances. Thus, in the temperate marginal seas, the growth and distribution of Prochlorococcus appears to be controlled by temperature and the mixing of coastal and open waters.

\section{Spatiotemporal variations of picocyanobacterial diversity}

In the temperate waters, the spatiotemporal changes in picocyanobacterial composition were remarkable (Table 2). In studies of seasonal variation of Synechococcus diversity, either Clade I/IV or Clade II dominates throughout the year (Fuller et al. 2006, Tai \& Palenik 2009, Post et al. 2011, Tai et al. 2011). However, our study showed that the dominant clade shifted from Clades I and IV (adapted to cold and coastal water) to the warm-water-adapted Clade II, demonstrating a distinct seasonal distribution in the ECS and the ES. In samples from cold waters $\left(<18^{\circ} \mathrm{C}\right)$, Clades I and IV dominated, accounting for 50 to $100 \%$ of the picocyanobacterial community. Most of the samples were obtained at Stns I and D5 in winter and spring. Thus, Clades I and IV seems to be major Synechococcus lineages in winter and spring below ca. $18^{\circ} \mathrm{C}$ in temperate marginal waters. However, at Stn H6, Clade II was dominant 
(58 to $85 \%$ ), followed by Clades I/IV (10 to $25 \%$ ). This difference may have been influenced by a branch of warm, oligotrophic water from the KC. On the contrary, in summer and autumn samples of Stns D5 and H6 affected by KC, Synechococcus Clades II and Prochlorococcus HLII dominated together, accounting for 49 to $92 \%$ of total picocyanobacteria (Table 2). Their dominance in summer and autumn was related to high temperature and oligotrophic conditions of the samples (Fig. 4C,D). However, in the summer sample of Stn I, Clade II was most dominant and Prochlorococcus was absent, likely due to the influence of Changjiang River water (Table 1).

Thus, in temperate waters, the seasonal change of picocyanobacterial diversity seems to be largely regulated by water temperature and trophic conditions. Changes in water properties and advection of picocyanobacteria derived by transport and mixing of adjacent water masses are also important in driving spatial variations of picocyanobacterial diversity in marginal temperate waters.

\section{Ecological niches of Synechococcus clades}

A higher total number of clades occurred in warm water. Clade III and, to a lesser extent, WPC1 were also abundant in surface water samples collected in the ECS during the summer (Table 2). The dominance of Clade III, followed by WPC1, was also reported in the oligotrophic Mediterranean Sea in the summer (Mella-Flores et al. 2011). The prevalence of Clade III in the Mediterranean Sea may be attributable to its competitive advantage in scavenging P under P stress (Scanlan et al. 2009, Mella-Flores et al. 2011). In the ECS, P limitation has been reported in association with salinity values $<30.5$ in summer (Wong et al. 1998). At Stn I in August, surface water showed a salinity of 29.5 and an N:P ratio of 33. Although the N:P ratio could not be estimated at Stn H6 due to undetectably low nutrient concentrations, the influence of CRDW was apparent considering the low salinity of 31.5. Thus, the relatively high proportion of Clades III and WPC1 in the samples may be explained by adaptation to P-limited conditions in the ECS. In the CCA analysis, Clades III and WPC1 were situated on the upper left (high temperature and low $\mathrm{N}$ preference), apart from all other clades (Fig. 5), suggesting that Synechococcus Clades III and WPC1 appear to be adapted to hightemperature and low-nutrient conditions, most likely P-limitation.
Clade 5.3-I was observed in all seasons, with the exception of several low-temperature samples collected in the spring, and this lineage often cooccurred with Clade II (Table 2). However, Clade 5.3-I members outnumbered Clade II members only in samples with temperatures of ca. $23^{\circ} \mathrm{C}$ and chl a concentrations of ca. $0.5 \mu \mathrm{g} \mathrm{l}^{-1}$. A recent study showed that SC5.3 is prevalent at the SCM depth at $23^{\circ} \mathrm{C}$ in warm off-shore stations in the South China Sea as well as in surface waters in the North Atlantic with temperatures of ca. $20^{\circ} \mathrm{C}$ (Huang et al. 2012). Thus, Clade 5.3-I seems to occupy a niche similar to that of Clade II but may be more competitive under less oligotrophic (i.e. mesotrophic) and relatively low-temperature conditions.

The global distribution of Clade VII is unclear due to the widespread use of a probe targeting combined Clades V/VI/VII, but previous works on the distribution of the combined Clades V/VI/VII in tropical and subtropical waters showed that Clade VII is widespread in oligotrophic waters (Zwirglmaier et al. 2007, 2008). Similarly, Clade VII was frequently present in waters affected by the $\mathrm{KC}$, suggesting that these picocyanobacteria are advected from warm, oligotrophic open waters. However, increased dominance $(34 \%)$ in the December sample at Stn H6 suggests that Clade VII members may grow opportunistically under elevated nutrient conditions in boundary waters affected by coastal or upwelling waters.

Clades I and IV appeared to be dominant in samples collected in the winter and spring as well as in samples from SCM depths in the summer (Table 2). However, the relative contributions of Clades I and IV varied greatly in the present study, with I:IV ratios ranging between 0.03 and 40, suggesting that the 2 clades in fact occupy distinct niches in cold coastal waters. To date, the factors controlling the relative abundances of Clades I and IV have not been determined (Zwirglmaier et al. 2008). However, in the present study, the ratios of I to IV showed a weak but significant positive relationship with the sum of nitrate and nitrite (Fig. 6), suggesting that $\mathrm{N}$ availability may be one of the factors determining their relative abundances.

\section{CONCLUSIONS}

Barcoded amplicon pyrosequencing was successfully applied to elucidate picocyanobacterial diversity and its distribution in marginal seas. Picocyanobacterial composition changed dynamically 


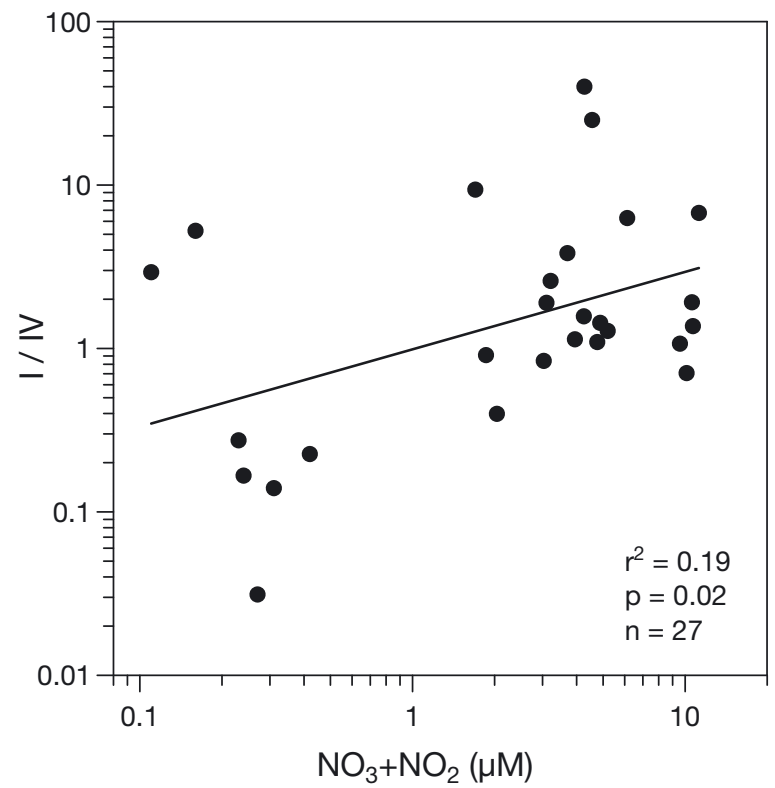

Fig. 6. Relationship between the sum of nitrate and nitrite concentrations and the abundance ratio of Clades I to IV in the present study

with season. In terms of an overall seasonal pattern, Clades I/IV and Clades II/HLII dominated during the cold and warm seasons, respectively. Furthermore, several picocyanobacterial clades were observed with less contribution. Temperature and nutrient levels likely play an important role in driving seasonal shifts in picocyanobacterial composition, and physical mixing between adjacent water masses is important in determining the physicochemical properties of water and thus the distribution of picocyanobacterial lineages. In addition, the distribution of Prochlorococcus, of which abundances could not be easily determined via flow cytometry, could be elucidated using the pyrosequencing method. Further application of this pyrosequencing method in high-throughput samples will broaden our understanding of the biogeography, ecological niches and adaptation to changing environments of various picocyanobacterial lineages.

Acknowledgements. We are grateful to Drs. D. Kim and P. Jang for providing nutrient data, Ms. M. Hahm for assistance with pyrosequencing, Dr. J. Park for helpful discussions on current systems and Dr. Karen E. Selph at the University of Hawaii for flow cytometric analyses. We also thank the editor and 4 anonymous reviewers for their helpful and constructive comments. The present study was supported by research programs PM57090, PM57420, PG48010 and PE99162 of the Korea Institute of Ocean Science and Technology and the Ministry of Oceans and Fisheries of Korea.

\section{LITERATURE CITED}

Ahlgren NA, Rocap G (2006) Culture isolation and cultureindependent clone libraries reveal new marine Synechococcus ecotypes with distinctive light and N physiologies. Appl Environ Microbiol 72:7193-7204

- Ahlgren NA, Rocap G (2012) Diversity and distribution of marine Synechococcus: multiple gene phylogenies for consensus classification and development of qPCR assays for sensitive measurement of clades in the ocean. Front Microbiol 3:00213

> Binladen J, Gilbert MT, Bollback JP, Panitz F and others (2007) The use of coded PCR primers enables highthroughput sequencing of multiple homolog amplification products by 454 parallel sequencing. PLoS ONE 2:e197

Cai H, Wang K, Huang S, Jiao N, Chen F (2010) Distinct patterns of picocyanobacterial communities in winter and summer in the Chesapeake Bay. Appl Environ Microbiol 76:2955-2960

> Chang KI, Teague WJ, Lyu SJ, Perkins HT and others (2004) Circulation and currents in the southwestern East/Japan Sea: overview and review. Prog Oceanogr 61:105-156

> Chen F, Wang K, Kan J, Suzuki MT, Wommack KE (2006) Diverse and unique picocyanobacteria in Chesapeake Bay, revealed by $16 \mathrm{~S}-23 \mathrm{~S}$ rRNA internal transcribed spacer sequences. Appl Environ Microbiol 72:2239-2243

> Choi DH (2012) Picocyanobacterial diversity and distribution during summer in the northern East China Sea. Ocean Polar Res 34:19-28 (in Korean)

Choi DH, Noh JH (2009) Phylogenetic diversity of Synechococcus strains isolated from the East China Sea and the East Sea. FEMS Microbiol Ecol 69:439-448

Choi DH, Noh JH, Hahm MS, Lee CM (2011) Picocyanobacterial abundances and diversity in surface water of the northwestern Pacific Ocean. Ocean Sci J 46:265-271

Fuller NJ, Marie D, Partensky F, Vaulot D, Post AF, Scanlan DJ (2003) Clade-specific 16S ribosomal DNA oligonucleotides reveal the predominance of a single marine Synechococcus clade throughout a stratified water column in the Red Sea. Appl Environ Microbiol 69:2430-2443

Fuller NJ, West NJ, Marie D, Yallop M, Rivlin T, Post AF, Scanlan DJ (2005) Dynamics of community structure and phosphate status of picocyanobacterial populations in the Gulf of Aqaba, Red Sea. Limnol Oceanogr 50: 363-375

Fuller NJ, Tarran GA, Yallop M, Orcutt KM, Scanlan DJ (2006) Molecular analysis of picocyanobacterial community structure along an Arabian Sea transect reveals distinct spatial separation of lineages. Limnol Oceanogr 51: 2515-2526

> Hamady M, Lozupone C, Knight R (2010) Fast UniFrac: facilitating high-throughput phylogenetic analyses of microbial communities including analysis of pyrosequencing and PhyloChip data. ISME J 4:17-27

> Haverkamp TH, Acinas SG, Doeleman M, Stomp M, Huisman J, Stal LJ (2008) Diversity and phylogeny of Baltic Sea picocyanobacteria inferred from their ITS and phycobiliprotein operons. Environ Microbiol 10:174-188

- Haverkamp TH, Schouten D, Doeleman M, Wollenzien U, Huisman J, Stal LJ (2009) Colorful microdiversity of Synechococcus strains (picocyanobacteria) isolated from the Baltic Sea. ISME J 3:397-408

> Huang S, Wilhelm SW, Harvey HR, Taylor K, Jiao N, Chen F (2012) Novel lineages of Prochlorococcus and Synechococcus in the global oceans. ISME J 6:285-297 
Ichikawa H, Beardsley R (2002) The current system in the Yellow and East China Seas. J Oceanogr 58:77-92

Jacquet S, Lennon JF, Marie D, Vaulot D (1998) Picoplankton population dynamics in coastal waters of the northwestern Mediterranean Sea. Limnol Oceanogr 43: 1916-1931

Jardillier L, Zubkov MV, Pearman J, Scanlan DJ (2010) Significant $\mathrm{CO}_{2}$ fixation by small prymnesiophytes in the subtropical and tropical northeast Atlantic Ocean. ISME J 4:1180-1192

Jenkins BD, Zehr JP, Gibson A, Campbell L (2006) Cyanobacterial assimilatory nitrate reductase gene diversity in coastal and oligotrophic marine environments. Environ Microbiol 8:2083-2095

$>$ Jing H, Liu H (2012) Phylogenetic composition of Prochlorococcus and Synechococcus in cold eddies of the South China Sea. Aquat Microb Ecol 65:207-219

> Jing H, Liu H, Suzuki K (2009a) Phylogenetic diversity of marine Synechococcus spp. in the Sea of Okhotsk. Aquat Microb Ecol 56:55-63

> Jing H, Zhang R, Pointing SB, Liu HB, Qian PY (2009b) Genetic diversity and temporal variation of the marine Synechococcus community in the subtropical coastal waters of Hong Kong. Can J Microbiol 55:311-318

> Johnson ZI, Zinser ER, Coe A, McNulty NP, Malcolm E, Woodward S, Chisholm SW (2006) Niche partitioning among Prochlorococcus ecotypes along ocean-scale environmental gradients. Science 311:1737-1740

Katoh K, Standley DM (2013) MAFFT Multiple Sequence Alignment Software Version 7: improvements in performance and usability. Mol Biol Evol 30:772-780

Lavin P, Gomez P, Gonzalez B, Ulloa O (2008) Diversity of the marine picocyanobacteria Prochlorococcus and Synechococcus assessed by terminal restriction fragment length polymorphisms of 16S-23S rRNA internal transcribed spacer sequences. Rev Chil Hist Nat 81:515-531

> Lavin P, Gonzalez B, Santibanez JF, Scanlan DJ, Ulloa O (2010) Novel lineages of Prochlorococcus thrive within the oxygen minimum zone of the eastern tropical South Pacific. Environ Microbiol Rep 2:728-738

Li WKW (1994) Primary production of prochlorophytes, cyanobacteria, and eukaryotic ultraphytoplankton: measurements from flow cytometric sorting. Limnol Oceanogr 39:169-175

> Liu HB, Nolla HA, Campbell L (1997) Prochlorococcus growth rate and contribution to primary production in the equatorial and subtropical North Pacific Ocean. Aquat Microb Ecol 12:39-47

Liu H, Dagg M, Campbell L, Urban-Rich J (2004) Picophytoplankton and bacterioplankton in the Mississippi River plume and its adjacent waters. Estuaries 27:147-156

Ludwig W, Strunk O, Westram R, Richter L and others (2004) ARB: a software environment for sequence data. Nucleic Acids Res 32:1363-1371

- Markowitz VM, Mavromatis K, Ivanova NN, Chen IM, Chu K, Kyrpides NC (2009) IMG ER: a system for microbial genome annotation expert review and curation. Bioinformatics 25:2271-2278

> Mazard S, Ostrowski M, Partensky F, Scanlan DJ (2012) Multi-locus sequence analysis, taxonomic resolution and biogeography of marine Synechococcus. Environ Microbiol 14:372-386

Mella-Flores D, Mazard S, Humily F, Partensky F and others (2011) Is the distribution of Prochlorococcus and Synechococcus ecotypes in the Mediterranean Sea affected by global warming? Biogeosciences 8:2785-2804

> Mitchell DA, Watts DR, Wimbush M, Teague WJ and others (2005) Upper circulation patterns in the Ulleung Basin. Deep-Sea Res II 52:1617-1638

> Moore LR, Goericke R, Chisholm SW (1995) Comparative physiology of Synechococcus and Prochlorococcus: influence of light and temperature on growth, pigments, fluorescence and absorptive properties. Mar Ecol Prog Ser 116:259-275

> Mühling M, Fuller NJ, Millard A, Somerfield PJ and others (2005) Genetic diversity of marine Synechococcus and co-occurring cyanophage communities: evidence for viral control of phytoplankton. Environ Microbiol 7 : 499-508

> Paerl RW, Foster RA, Jenkins BD, Montoya JP, Zehr JP (2008) Phylogenetic diversity of cyanobacterial narB genes from various marine habitats. Environ Microbiol 10:3377-3387

Parsons TR, Maita Y, Lalli CM (1984) A manual of chemical and biological methods for seawater analysis. Pergamon Press, Oxford

> Partensky F, Hess WR, Vaulot D (1999) Prochlorococcus, a marine photosynthetic prokaryote of global significance. Microbiol Mol Biol Rev 63:106-127

Penno S, Lindell D, Post AF (2006) Diversity of Synechococcus and Prochlorococcus populations determined from DNA sequences of the N-regulatory gene ntcA. Environ Microbiol 8:1200-1211

Post AF, Penno S, Zandbank K, Paytan A, Huse SM, Welch DM (2011) Long term seasonal dynamics of Synechococcus population structure in the Gulf of Aqaba, Northern Red Sea. Front Microbiol 2:00131

> Qian PY, Wang Y, Lee OO, Lau SCK and others (2011) Vertical stratification of microbial communities in the Red Sea revealed by $16 \mathrm{~S}$ rDNA pyrosequencing. ISME J 5: 507-518

> Quince C, Lanzen A, Davenport RJ, Turnbaugh PJ (2011) Removing noise from pyrosequenced amplicons. BMC Bioinformatics 12:38

> Rocap G, Distel DL, Waterbury JB, Chisholm SW (2002) Resolution of Prochlorococcus and Synechococcus ecotypes by using 16S-23S ribosomal DNA internal transcribed spacer sequences. Appl Environ Microbiol 68: 1180-1191

Scanlan DJ, Ostrowski M, Mazard S, Dufresne A and others (2009) Ecological genomics of marine picocyanobacteria. Microbiol Mol Biol Rev 73:249-299

> Schloss PD, Westcott SL, Ryabin T, Hall JR and others (2009) Introducing mothur: open-source, platform-independent, community-supported software for describing and comparing microbial communities. Appl Environ Microbiol 75:7537-7541

Somerville CC, Knight IT, Straube WL, Colwell RR (1989) Simple, rapid method for direct isolation of nucleic acids from aquatic environments. Appl Environ Microbiol 55: $548-554$

Sommer U, Lengfellner K (2008) Climate change and the timing, magnitude, and composition of the phytoplankton spring bloom. Glob Change Biol 14:1199-1208

Strickland JDH, Parsons TR (1972) A practical handbook of seawater analysis, 2nd edn. Bull Fish Res Board Can 167

Tai V, Palenik B (2009) Temporal variation of Synechococcus clades at a coastal Pacific Ocean monitoring site. ISME J 3:903-915

Tai V, Burton RS, Palenik B (2011) Temporal and spatial dis- 
tributions of marine Synechococcus in the Southern California Bight assessed by hybridization to bead-arrays. Mar Ecol Prog Ser 426:133-147

Toledo G, Palenik B (1997) Synechococcus diversity in the California current as seen by RNA polymerase (rpoC1) gene sequences of isolated strains. Appl Environ Microbiol 63:4298-4303

Wong GTF, Gong GC, Liu KK, Pai SC (1989) 'Excess nitrate' in the East China Sea. Estuar Coast Shelf Sci 46:411-428

Editorial responsibility: Daniel Vaulot, Roscoff, France
Zwirglmaier K, Heywood JL, Chamberlain K, Woodward EMS, Zubkov MV, Scanlan DJ (2007) Basin-scale distribution patterns of picocyanobacterial lineages in the Atlantic Ocean. Environ Microbiol 9:1278-1290

Zwirglmaier K, Jardillier L, Ostrowski M, Mazard S and others (2008) Global phylogeography of marine Synechococcus and Prochlorococcus reveals a distinct partitioning of lineages among oceanic biomes. Environ Microbiol 10:147-161

Submitted: June 11, 2013; Accepted: September 26, 2013 Proofs received from author(s): November 20, 2013 